\title{
Distinguishing the Effect of Oil Shocks on the Global Economy: A Threshold Regression Approach
}

\author{
Khang Yi Sim and Siok Kun Sek* \\ School of Mathematical Sciences, Universiti Sains Malaysia \\ 11800 Minden, Penang, Malaysia \\ *Corresponding author: sksek@usm.my
}

Article history

Received: 10 November 2019

Received in revised form: 21 November 2019

Accepted: 19 December 2019

Published online: 31 December 2019

\begin{abstract}
The effect of oil shock on the global economy is evident through many studies. However, the effect is heterogeneous over time. One of the reasons that lead to such different impacts is due to the oil source that is either the oil shock is demand or supplydriven. Applying the structural vector autoregressive (SVAR) model to generate the three oil shocks based on the three oil sources (oil supply, oil demand and oil specificdemand), we extended the examination on the effect of oil shock on the global economy using the threshold regression. Our results reveal the threshold effects of oil directly and indirectly on the global economy. The impacts of oil shocks differ across sectors, implying oil intensity, as well as oil sources, are the factors that determine the impact of oil shocks on the global economy. Overall, the oil specific-demand shock is more influential among the three oil shocks. Hence, the global economy is oil demand-driven. Besides that, the impact of oil is relatively large in the energy sector when compared to the non-energy sector and precious metals industry. Despite that, the impact of oil shocks is small if compared to the non-oil shocks such as exchange rate changes and global consumer price inflation shock. Consequently, non-oil shocks are the main determinants of the global economic fluctuation. The study leads to a better understanding of the transmission of oil shock and its sources, the interaction between oil and economic indicators and the policy implication due to oil dependency/ intensity.
\end{abstract}

Keywords Oil shock; oil demand; oil supply; threshold regression; commodity price

Mathematics Subject Classification 62J02, 91G70

\section{Introduction}

For decades, oil has been the main commercial energy source in the world, and it is agreed that oil will keep on to be the main energy resource in the 21st century. Oil was one of the most crucial world energy mixes since after the Second World War, with 60\% to $70 \%$ of world oil consumption by the Organisation for Economic Co-operation and Development (OECD) [1]. At present, the consumption of oil accounts for about $40 \%$ of the global energy mix [1-2]. 
The influence of oil on the global economy is evident through many studies. Inflation will usually follow the directions of the change in oil prices. This relationship was evident in the 1970s when the nominal price of oil increased from $\$ 3$ before the 1973 oil crisis to approximately $\$ 40$ during the 1979 oil crisis [3]. As a result, the consumer price index (CPI), a key measurement for inflation was doubled by the end of 1980 as compared to early 1972 . On the other hand, the impact of oil shock might vary across industries, countries and time periods. The variation of results can be discussed from several issues. The first issue is related to data construction. Previous studies applied oil price data to proxy for oil shock in analysing the impact of the oil shock on an economy. This traditional approach explained oil price increases due to oil production (oil supply shock) alone. To understand better the heterogeneous effect of oil shock, Kilian [4] took the first initiative to decompose the oil shock into three components i.e.,oil supply, oil demand and oil specific-demand shocks. He claimed that the traditional approach showed misleading results and demonstrated that the global aggregate demand and precautionary demand shocks dominated the oil shocks that explained the global stagflation well, while oil supply shock only had a minor effect. The second issue is related to the modelling approach. Most studies applied a linear modelling approach. Indeed, economic theories provided good reasons for the asymmetric effect of an oil shock. The impact of oil price increases could be different from the effect of oil price decreases. In the presence of an asymmetric effect, linear modelling might produce inaccurate and misleading results. In filling the shortcoming from previous studies, this paper seeks to apply the data decomposition and the dynamic threshold regression of Hansen[5] to study the effect of oil shock on the global economy.

The main objective of this study is to examine the effect of oil shock based on oil source origins (demand versus supply origins) following the approach of Kilian [4]. In particular, the dynamic threshold regression of Hansen [5] is used to capture the nonlinear/ threshold effect in the model. The results are compared across sectors in revealing the main factors contributing to global economic fluctuation. The analysis is based on global data. The results detect the time-varying effect of a variety of shocks between two regimes triggered by threshold variables. Threshold regression provides more informative and accurate estimates compared to the linear model. The oil specific-demand shock has a greater impact on the global economy than the oil supply shock while the oil aggregate demand shock shows no significant impact. The impact of oil shocks is small if compared to the non-oil shocks such as exchange rate changes and CPI inflation shock.

\section{Theoretical Model and Literature Review}

\subsection{Theoretical Framework}

\subsubsection{The Transmission Channels of Oil Effect}

According to Kilian [6], the economic theories of oil price shock transmissions differentiate the direct and indirect effects of exogenous oil price shock. The direct effect of an oil shock results in symmetric responses of the economy, whereas the indirect effects may lead to economic asymmetry, depending on the unexpected increase or decrease in the oil price. The macroeconomic effects of exogenous changes in the price of imported crude oil are transmitted through three main channels which are the supply channel of transmission and demand channel 
of transmission, relating to the direct effects, and systematic monetary policy responses for indirect effects.

One of the direct effects is the decrease in the purchasing power of the local household since income is transferred out of the country when crude oil is imported [6]. It is similar to an adverse aggregate demand shock. The other direct effect is the increase in the cost of domestic production, making oil a factor of production as well as capital and labour. This effect is similar to an unfavourable aggregate supply shock. Other than the direct effects on the real gross domestic product (GDP), the exogenous oil price shock also has immediate impacts on inflation.

By the supply channel of transmission of oil price shock, the marginal production costs are increased by oil price shocks, thereby reducing the capacity utilisation of corporations [7]. Thus, the output from the cooperation is reduced in the short term and the rate of unemployment is increased; in spite of that, the decreased in production caused by a decrease in capacity utilisation can be rapidly recovered. Besides, a perpetual rise in oil price volatility may cause the upcoming capacity to be constantly lower [8]. As a result, the unpredictability and disturbances of oil price may delay investment decisions. When oil becomes comparatively more expensive than other intermediate goods, the energy-demanding industries will diminish their production while less energy demanding industries will flourish. Such adjustments in the industries will lead to high costs, a high rate of unemployment and under-utilisation of resources.

Through the demand channel of transmission, the increase in the price of oil causes the commodity prices to increase, leading to reduction in the purchasing power of money and increased living costs [8]. The economy is affected by energy price shocks when the expenditures on goods and services other than energy are reduced [6]. This is because higher energy prices will likely shrink the households' income after electricity bills are paid off. The decrease in household expenses could be magnified by the rise in operating cost of energy-consuming durables, specifically purchases of automobile.

Policy response is another transmission channel for the oil effect. A rise in oil prices will increase the cost of production; consequently, the price of final products will increase [9]. Inflation often arises when retaining the price of non-energy based products, for a given aggregate demand level, will drive the economy into recession. Then, the policymakers can implement a contractionary monetary policy in controlling inflation and an expansionary policy to overcome economic recession. In controlling the inflation caused by cost shocks such as increases in the price of oil, the contractionary monetary policy would reduce the output in the long term by raising the interest rate and reducing the investment [7].

L'oeillet and Licheron [10] stated that rising oil prices increase inflation rates through three ways which are direct, indirect and "second-round" effects, where they are closely related and dependent on each other. The direct effect of oil prices on domestic products happens when the prices of crude oil are transferred on the prices of refined products which are included in the consumer price index (CPI). The indirect effect of oil prices conveys from producer prices to consumer prices which shifts the energy prices to higher values. Lastly, the second-round effect and a wage-price spiral are generated when the increase in oil prices raises the expectations of inflation and wages due to the concerns of direct and indirect effects (first-round effects). 


\subsubsection{The Oil Decomposition and Oil Shock Modelling}

Kilian [4] claimed that oil shock can be distinguished based on the shock origins whether it is demand or supply-driven. Rather than using oil price data, Kilian [4] decomposed the oil effect into three main components, namely the percentage change in global crude oil production, the index of real economic activity and the real price of oil. Thus, a structural vector autoregressive (SVAR) model of the global crude oil market is proposed.

These shocks have their respective economic interpretations [4]. The first type, oil supply shocks, are interpreted as shocks to the existing physical availability of crude oil. Second, aggregate demand shocks are interpreted as shocks to the existing demand for crude oil caused by fluctuations in the worldwide commercial cycle that could not be explained by oil supply shocks. Third, precautionary demand shocks are referred to as shocks caused by changes in the precautionary demand for oil that could not be clarified by both oil supply shocks and aggregate demand shocks. The unexpected changes in the real price of crude oil had been decomposed into three mutually orthogonal components with the economic interpretations to represent the three oil sources. The percentage change in global crude oil production is used to represent the oil supply, the index of real economic activity is used to represent the aggregate oil demand, and the real price of oil is used to represent the oil specific-demand.

Following Kilian [4], the monthly index of global real economic activity was derived based on the data of dry cargo single voyage ocean freight rates, which were published in the monthly report on "Shipping Statistics and Economics" by Drewry Shipping Consultants Ltd. The unit used in freight rates is U.S. dollar per metric ton. The steps for constructing the index are as follows. First, the period-to-period growth rates of individual freight rates were calculated. Then, the simple averages of these growth rates were computed and cumulative sums were taken, having normalized January of 1968, which is the first data to unity. Next, this series was deflated with the U.S. consumer price index. Lastly, the real index was detrended.

According to Kilian [4], the SVAR model of the global crude oil market can be represented as $\mathbf{A}_{\mathbf{0}} \mathbf{z}_{\mathbf{t}}=\boldsymbol{\alpha}+\sum_{\mathbf{i}=\mathbf{1}}^{\mathbf{2 4}} \mathbf{A}_{\mathbf{i}} \mathbf{z}_{\mathbf{t}-\mathbf{i}}+\boldsymbol{\varepsilon}_{\mathbf{t}}$ where $\boldsymbol{\varepsilon}_{\mathbf{t}}$ denotes the vector of serially and mutually uncorrelated structural innovations, and $\mathbf{z}_{\mathbf{t}}=\left(\Delta \operatorname{prod}_{t}, \operatorname{rea}_{t}, \operatorname{rpo}_{t}\right)^{\prime}$, where $\Delta \operatorname{prod}_{t}$ is the percent change in global crude oil production, $r e a_{t}$ is the index of real economic activity, and $r p o_{t}$ is the real price of oil. The $\Delta \operatorname{prod}_{t}$ series is expressed in the first differenced form while the rea $a_{t}$ and $r p o_{t}$ series are expressed in the $\log$ form. Let $\mathbf{A}_{\mathbf{0}}^{-\mathbf{1}}$ has a recursive structure such that the reduced form errors $\mathbf{e}_{\mathbf{t}}$ can be decomposed according to $\mathbf{e}_{\mathbf{t}}=\mathbf{A}_{\mathbf{0}}^{-1} \varepsilon_{\mathbf{t}}$, such that:

$$
\mathbf{e}_{\mathbf{t}} \equiv\left(\begin{array}{c}
e_{t}^{\Delta \text { prod }} \\
e_{t}^{r e a} \\
e_{t}^{r p o}
\end{array}\right)=\left[\begin{array}{ccc}
a_{11} & 0 & 0 \\
a_{21} & a_{22} & 0 \\
a_{31} & a_{32} & a_{33}
\end{array}\right]\left(\begin{array}{c}
\varepsilon_{t}^{\text {oil supply shock }} \\
\varepsilon_{t}^{\text {aggregatedemand shock }} \\
\varepsilon_{t}^{\text {oil specific-demandshock }}
\end{array}\right)
$$

\subsection{Empirical Findings}

The previous studies showed oil effects differ across countries, sectors and periods. For instance, oil price shocks have a greater impact on net oil-importing countries than oil-exporting countries. Besides that, the oil intensive industries are more sensitive to oil price changes. The previous studies also mentioned that the magnitude of oil effects is not similar across periods. In fact, the oil effects had diminished over time. 


\subsubsection{Heterogeneous Effects (Countries, Sectors, Periods)}

Previous studies found that oil effect is heterogeneous across countries and sectors, and the results also vary over time. In terms of countries, the results showed that the oil effect felt in oil-importing countries is much larger than that felt in oil-exporting countries. For instance, Baumeister et al. [11] discovered that the economic activities of net oil-importing countries such as Europe, the United States, Switzerland and Japan decline permanently due to the adverse supply shock. By contrast, for net oil-exporting countries, namely the United Kingdom, Canada, Norway and Australia, the impact on the economic activities was not significant or even positive. Peersman and Robays [12] did a similar analysis and obtained identical conclusions as Baumeister et al. [11].

In addition, Jiménez-Rodríguez and Sánchez [13] also found the same for the oil-importing countries investigated. However, among the two oil-exporting countries, the rise in oil prices has positive impacts on Norway but negative impacts on the United Kingdom. Filis and Chatziantoniou [14] claimed that for the net oil-importing countries, the United Kingdom and Portugal faced persistent oil price shocks as compared to France and Germany, with positive oil price shocks causing positive response of inflation. For the net oil-exporting countries, they reported that both Russia and Norway exhibited positive responses of inflation to the positive oil price shocks with Russia having an immediate and higher magnitude of inflation as opposed to Norway. They also noticed that the oil price shocks had negative impacts on all stock markets in their study except for the Norwegian stock market.

Previous studies also reported different results across sectors. The sectors that are more oil intensive are more affected by oil prices. For example, Mensi [15] noted that the upward trend of oil prices impact the petrochemical sector the most among the Saudi stock markets while hotel and tourism industries are the least affected sectors in Saudi Arabia. Arouri and Nguyen [16] also argued that the oil and gas sector is one of the sectors which has positive sensitivity to the changes in oil prices in Europe; conversely, the food and beverage sector is among the sectors with negative sensitivity to oil prices.

Finally, the results also differ over time. Some studies claimed that the oil effect had declined over time since the mid-1980s. To investigate whether the economic impact of oil shocks had changed across periods, Baumeister et al. [11] studied on two different periods with quarterly data for the United States which are 1970-1985 (the 1970s) and 1986-2008 (the 1990s). They realised that as compared to the 1970s, the oil supply shock had less impact on economic activity and inflation in the latter period. Other studies also revealed that the macroeconomic effects of oil price shocks had diminished over time $[17,18]$

\subsubsection{Oil Shock on Economic Indicators}

Previous studies have proven the significant effect of oil on economic performances such as stock performance, inflation, gross domestic product and commodity. For example, the findings from Arouri and Nguyen [16] who employed weekly stock market sector indices for 1998-2008 indicated that the changes in oil prices and stock markets have significant associations for most European sectors. Besides that, Al-hajj et al. [19] found that the oil price shocks had negatively impacted the stock market returns in most circumstances for Malaysia irrespective of positive or negative oil shocks. Also, the oil source origin shocks have different impacts on the stock market performance. Bastianin et al. [20] discovered that the oil price shock which originated 
from the demand side of marketplace is the key factor of stock market volatility. They observed that the aggregate demand shocks affect the volatility by at least $10 \%$ of its total in the G7 countries in the long run. On the other hand, oil supply shocks do not impact the stock market volatility.

Many previous studies claimed that a positive oil price shock induces a higher level of inflation [21-23]. However, the findings from Olomola and Adejumo [24] revealed that oil price shocks do not considerably affect the inflation rate in Nigeria. In addition, there are studies which argued that the overall inflation is not significantly affected by the oil price effects; yet, the oil price shocks impacted the core inflation considerably before 1980 but the impact was less significant for 1980 onwards [17,25]. Lioudis [3] also pointed out that the level of inflation follows the direction of movement in the price of oil, and this relationship was evident in the 1970 s although it started to weaken after the 1980s.

Gross domestic product (GDP) is also influenced by the price of oil. Some studies disclosed that the price of oil has a positive influence on the GDP. For example, Al-mulali and Sab [26] disclosed that oil prices had positively affected the GDP in Qatar with a higher level of inflation. Additionally, Gbatu et al. [27] argued that in the short run, oil shocks had positive effects on the real GDP in Liberia, a small oil-importing economy,as the oil price increases do not result in a significant drop in real GDP from both supply and demand sides. Conversely, the findings from Trang et al. [22] demonstrated that the GDP in Vietnam is negatively influenced by the price of oil in the long term. Baumeister et al. [11] claimed that the effect of oil shock on real GDP is based on the oil source origins. They noted that the real GDP of all economies increased temporarily with the oil prices when the oil demand shock is driven by economic activity, while the real GDP decreased temporarily due to the oil specific-demand shock. However, the impact of exogenous oil supply shock on the real GDP appeared to be very different across countries when the oil price increased.

Previous studies have proven the effect of oil shocks on the commodity. For instance, the findings from Zhang and Chen [28] pointed out that both expected and unexpected fluctuations in oil prices impact the aggregate commodity market in China. Melichar and Atems [29] discovered that the global commodity price index is driven by the effect of oil shock differently based on the oil sources origins. They reported that oil demand shocks increased the energy and non-energy commodity price indices, while oil supply shocks had little impact on the commodity price index. By contrast, the study from Fowowe [30] revealed that global oil prices do not affect the prices of agricultural commodities in South Africa.

\subsubsection{Linear Versus Non-Linear Effects}

Earlier studies that examined the oil effect were mainly based on linear modelling. Linear modelling is subjected to limitations such as failure to detect the asymmetric effect, less accurate and may not show the real economic situation. Asymmetric or non-linear modelling might depict the reality better as economic relationships might change due to sudden shock or structural change. The reason behind this is that the linear modelling is based on timeinvariant regressions where the explanatory variables have the same effect on the dependent variable throughout [31].

A few studies have shown the asymmetric effect of oil price shocks with oil price increases having larger impacts on the economic activities than oil price decreases [6,13,32]. For instance, Jiménez-Rodríguez and Sánchez [13] conducted the multivariate VAR analysis using both linear 
and non-linear models to identify the impacts of oil price shocks on the real economic activities for some OECD countries. They noted that there are non-linear effects of oil prices on the real economic activities with different impacts on the real output when the oil prices increased and decreased. There is a larger effect of oil price on GDP growth when oil price increases than when oil price decreases. This contradicts the assumption of symmetrical impacts of oil prices on the real activities in a linear approach. Regarding the magnitude of the responses, their results exhibited that non-linear specifications have a tendency to produce greater real impacts of oil price shocks in contrast to the linear model.

Moreover, Sotoudeh and Worthington [33] used linear and non-linear models to identify the causal relationships between oil price changes and consumer prices for a few net oilconsuming and producing countries. They reported that the bias-corrected panel Granger linear causality test provides no evidence on the linear causal relationships, while countryspecific linear causality tests showed that there is stronger linear causality in net oil-consuming countries. As they are aware of the weakness of linear models in detecting all likely relationships within the economic variables, they applied two non-linear causality tests. From the non-linear parametric Mackey-Glass model, they observed that the non-linear causality only occurred in Denmark and Canada, while for the non-linear nonparametric Hiemstra-Jones model, strong non-linear causality is found in all net oil-producing countries which are Canada, Norway and Mexico, and three of the seven net oil-consuming countries, particularly Germany, Sweden and United States. Furthermore, non-linear causal relationships are mostly asymmetric.

Oyelami [34] applied both linear and non-linear autoregressive distributed lag model (ARDL) modelling techniques in the study. The author disclosed that the changes in oil prices had considerably impacted Nigeria key macroeconomic variables. Regarding the relationship between oil price and output performance, the author found that the asymmetric effect is present in the long run only where negative changes in oil prices had a greater response to the output performance. However, there is no asymmetric effect in both the short run and the long run for the effect of oil price changes on the general price in Nigeria. In the case of oil price and exchange rate relationship, the linear and non-linear estimations provided different results in the short-run relationship. From the linear estimation, the increase in oil price increased the exchange rate in the short run but not in the long run which suggested that the inverse relationship only occurred in the long run. By contrast, the non-linear estimation showed evidence of asymmetric effect and the inverse relationship between oil price movement and exchange rate in both the short run and the long run.

\section{Data and Methodology}

\subsection{Data}

For this study, there are three components of oil sources and three non-oil sources used to generate the series of shocks. The oil sources are constructed in the following way. Following Kilian [4] and Güntner and Linsbauer [35], the change in the global crude oil production (DPROD) is constructed as the annualised change in the natural log of world crude oil production (thousand barrels per day) collected from the U.S. Energy Information Administration (EIA). The real economic activity index (REAL) is obtained from Kilian [36]. Finally, the natural log of the real price of oil (LRPO) is expressed as the natural log of the EIA's monthly refiner acquisition cost of imported crude oil (Dollars per barrel) deflated by the 
natural log of the U.S. CPI where the data is collected from the Bureau of Labour Statistics. The three components of non-oil sources are real effective exchange rate (DREER), industrial production index $(D I P I)$ and consumer price index $(D C P I)$, where the data for these three components are obtained from the website of Global Economic Monitor [37].

Table 1: Summaries of the Variables

\begin{tabular}{|c|c|c|}
\hline Variable & Description/ Proxy & Formula/ Remark \\
\hline$D P R O D$ & Proxy for oil supply & $\begin{array}{l}\text { Change in the natural log of world } \\
\text { crude oil production }\end{array}$ \\
\hline$R E A L$ & Proxy for oil aggregate demand & Real economic activity index \\
\hline$L R P O$ & Proxy for oil specific-demand & Natural log of the real price of oil \\
\hline$D R P O$ & Changes in $L R P O$ & First differenced of $L R P O$ \\
\hline DREER & Proxy for real effective exchange rate & $\begin{array}{c}\text { Change in natural log of real effective } \\
\text { exchange rate }\end{array}$ \\
\hline$D I P I$ & $\begin{array}{l}\text { Proxy for industrial production index } \\
\text { (IPI) inflation }\end{array}$ & $\begin{array}{c}\text { Change in natural log of industrial } \\
\text { production index }\end{array}$ \\
\hline$D C P I$ & $\begin{array}{c}\text { Proxy for consumer price index (CPI) } \\
\text { inflation }\end{array}$ & $\begin{array}{c}\text { Change in natural log of consumer } \\
\text { price index }\end{array}$ \\
\hline$D R S V I$ & Proxy for retail sales volume index & $\begin{array}{c}\text { Change in natural log of retail sales } \\
\text { volume index }\end{array}$ \\
\hline$D E N E R$ & Proxy for energy sector & $\begin{array}{l}\text { Change in natural log of commodity } \\
\text { price index (energy) }\end{array}$ \\
\hline DNONE & Proxy for non-energy sector & $\begin{array}{c}\text { Change in natural log of commodity } \\
\text { price index (non-energy) }\end{array}$ \\
\hline DPMET & Proxy for precious metals industry & $\begin{array}{c}\text { Change in natural log of commodity } \\
\text { price index (precious metals) }\end{array}$ \\
\hline$U_{-} D P R O D$ & The shock of oil supply & Generated from SVAR model \\
\hline$U_{-} R E A L$ & The shock of oil aggregate demand & Generated from SVAR model \\
\hline$U_{-} D R P O$ & The shock of oil specific-demand & Generated from SVAR model \\
\hline$U_{-} D R E E R$ & $\begin{array}{c}\text { The shock of real effective exchange } \\
\text { rate }\end{array}$ & Generated from SVAR model \\
\hline$U_{-} D I P I$ & $\begin{array}{c}\text { The shock of industrial production } \\
\text { index }\end{array}$ & Generated from SVAR model \\
\hline$U_{-} D C P I$ & The shock of consumer price index & Generated from SVAR model \\
\hline
\end{tabular}

The data used in the study are in monthly frequency where only world data is focused. The period coverage of raw data is 1994M2-2018M2. After adjusting for data construction in the growth rate (first differencing) and lag specification using structural VAR estimation, the data is shortened to 1994M12-2018M2. The six series of shocks generated are used in the threshold regression as the independent variables, which are $U_{-} D P R O D, U_{-} R E A L, U_{-} D R P O, U_{-} D R E E R$, $U_{-} D I P I$ and $U_{-} D C P I$. The dependent variables of the threshold regression consist of aggregated data and sectoral data (disaggregated). The variables DREER, DIPI, DCPI and DRSVI are the aggregated data, while the commodity price index (DENER, DNONE and DPMET) is the 
sectoral data. The monthly data of commodity price indices are based on nominal U.S. dollars. Since there are five dependent variables, therefore there are five main models for the threshold regression to be estimated. The data for the variable DRSVI is also obtained from the website of Global Economic Monitor [37], but the data for DENER, DNONE and DPMET are taken from the website of Commodity Markets [38]. Table 1 indicates the description/ proxy and formula/ remark for all variables used in the estimations.

\subsection{Methodology}

There are two phases in the analysis. In Phase I, the shocks for three oil components are constructed using structural VAR or SVAR model. The analysis in Phase II is to estimate the threshold regression of Hansen [5].

\subsubsection{Structural VAR Estimation}

The SVAR Blanchard-Quah Model which was presented by Blanchard and Quah [39] is estimated. The Blanchard-Quah identification imposed the long-run restrictions on the cumulative impulse response function. The total number of restrictions is $K(K-1) / 2=15$, where $K$ is the number of variables and $K=6$. The long-run impact matrix can be written as follows: $\mathbf{e}_{\mathbf{t}}=\mathbf{C}(\mathbf{1}) \varepsilon_{\mathbf{t}}$, where $\mathbf{C}(\mathbf{1})$ is the long-run matrix of lower triangular Cholesky decomposition, $\mathbf{C}(\mathbf{L})$. $\mathbf{e}_{\mathbf{t}}$ is the error term for six endogenous variables, which are DPROD, $R E A L, D R P O, D R E E R, D I P I$ and $D C P I . \varepsilon_{\mathrm{t}}$ is the vector of shocks or structural innovations, specifically, U-DPROD, U_REAL, U_DRPO, U_REER, U_DIPI and U_DCPI.

Note that the identified accumulated long-run impact matrix is in lower triangular Cholesky decomposition. The structure of shocks is affected by the ordering of variables. A shock in the uppermost variable will give impact on all variables underneath but it will not receive impacts from those variables except its own shock. A shock in the following variable will give impact on all variables below it but not on the variables above it; however, it will receive impacts from all variables above it and its own shock but not from the variables below it. This rule of interpretation of the matrix is applied to all succeeding variables. The orderings for the variables are based on Kilian [4] and Kilian and Park [40]. The impulse response function (IRF) and forecast error variance decomposition (FEVD) are some common tools to investigate the associations between variables and to interpret the VAR model [41]

\subsubsection{Threshold Estimation}

After the SVAR estimation is performed and the shocks series are generated, the estimation of threshold regression of Hansen (2000) is performed. From the previous paper, the author found that there is no practical way to construct confidence intervals for the threshold model. Consequently, the author derived an asymptotic approximation to the distribution of least square estimate $\hat{\gamma}$ of threshold parameter, $\gamma$. The threshold regression model is as follows:

$$
\begin{aligned}
& Y_{i}=\theta_{1}^{\prime} X_{i}+e_{i}, \text { for } q_{i} \leq \gamma, \\
& Y_{i}=\theta_{2}^{\prime} X_{i}+e_{i}, \text { for } q_{i}>\gamma,
\end{aligned}
$$

where $e_{i}$ is the regression error, $q_{i}$ is the threshold variable, and $\gamma$ is the threshold value. The observed sample is $\left\{Y_{i}, X_{i}, q_{i}\right\}_{i=1}^{n}$, where $i$ is the observations or time series data. The threshold variable is used to split the sample into two groups, which also named as classes or regimes. 
The null hypothesis of no threshold effect, that is, $H_{0}: \gamma=\gamma_{0}$ is tested. Assumes that the error term $e_{i}$ is i.i.d. $N\left(0, \sigma^{2}\right)$ then the likelihood ratiostatistic is $L R_{n}(\gamma)=n \times$ $\left[S_{n}(\gamma)-S_{n}(\hat{\gamma})\right] / S_{n}(\hat{\gamma})$, where $S_{n}(\gamma)$ is the concentrated sum of squared errors function based on the least square estimate and $\hat{\gamma}$ is the value which minimizes the $S_{n}(\gamma)$. The likelihood ratio test of $H_{0}$ is rejected when $L R_{n}\left(\gamma_{0}\right)$ is large. The asymptotic $p$-value for the likelihood ratio test is:

$$
p_{n}=1-\left\{1-\exp \left[-\frac{1}{2} L R_{n}\left(\gamma_{0}\right)^{2}\right]\right\}^{2} \text {. }
$$

\section{Results}

\subsection{Preliminary Test}

Before the series of shocks are generated, the variables for oil sources and non-oil sources, namely DPROD, REAL, LRPO, DREER, DIPI and DCPI are tested for stationarity over the period 1994M2-2018M2 by using Augmented Dickey-Fuller (ADF), Phillips-Perron (PP) and Kwiatkowski-Philips-Schmidt-Shin (KPSS) unit-root tests. ADF and PP tests are based on the null hypothesis of non-stationarity while KPSS is based on the null hypothesis of stationarity. The rejections of null hypothesis in ADF and PP tests indicate that the series is stationary while the rejection in KPSS means the series is not stationary. The results (Table 2) reveal that all variables are stationary at levels except $L R P O$ which is stationary after first differencing. Therefore, all variables as defined will enter the regression analysis except $L R P O$ will be used in the first differenced form. The second panel of Table 2 is the results of unit-root tests for all shock series generated from the SVAR model. All shocks are stationary at levels.

\subsection{Result of Estimations}

\subsubsection{Structural VAR Estimation}

The structural VAR or SVAR model has nine endogenous lags as suggested by the Akaike Information Criterion (AIC) [42]. The estimated contemporaneous impact matrix is as follows:

$$
\left[\begin{array}{cccccc}
0.0333^{* * *} & 0.0079 & 0.0005 & -0.0021 & 0.0007 & -0.0023 \\
-2.2210 & 6.9649^{* * *} & -1.1717 & 2.5139^{* * *} & -1.1822^{* *} & -1.6464 * \\
-0.0057 & 0.0136 & 0.0695^{* * *} & 0.0009 & -0.0184^{* * *} & 0.0062 \\
0.0005 & -0.0013^{* * *} & -0.0004 & 0.0027^{* * *} & -0.0001 & -0.0009^{* *} \\
-0.0019 & 0.0046^{*} & 0.0078^{* * *} & 0.0024 & 0.0210^{* * *} & -0.0011 \\
-0.0002 & 0.0002 & 0.0005 * & 0.0009^{* * *} & -0.0004 & 0.0020^{* * *}
\end{array}\right] .
$$

The estimated identified long-run impact matrix is as follows:

$$
\left[\begin{array}{cccccc}
0.4448^{* *} & 0 & 0 & 0 & 0 & 0 \\
-117.7952 & 138.5613^{* * *} & 0 & 0 & 0 & 0 \\
-0.0411 & 0.0235 & 0.0701^{* * *} & 0 & 0 & 0 \\
0.0036 & -0.0046^{* *} & 0.0006 & 0.0050 * * * & 0 & 0 \\
0.0134 & -0.0019 & 0.0090^{* * *} & 0.0050 * * & 0.0175 * * * & 0 \\
0.0079 & -0.0059 & -0.0003 & 0.0043^{* * *} & 0.0013 & 0.0078^{* * *}
\end{array}\right] .
$$

Note that $* * *$, and $* * *$ indicate the significance levels at $10 \%, 5 \%$ and $1 \%$ respectively. The ordering of variables is essential in the structural VAR model. There is a total of six variables 
Table 2: Unit-Root Tests

\begin{tabular}{cccc}
\hline Variable & ADF & PP & KPSS \\
\hline$D P R O D$ & -2.2046 & $-3.8833^{* * *}$ & $0.8766^{* * *}$ \\
$R E A L$ & $-3.0465^{* *}$ & $-2.8363^{*}$ & 0.3188 \\
LRPO & -2.0899 & -1.9522 & $1.2694^{* * *}$ \\
$D R P O$ & $-13.1293^{* * *}$ & $-13.1770^{* * *}$ & 0.1014 \\
\hline$D R E E R$ & $-12.2854^{* * *}$ & $-12.5813^{* * *}$ & 0.3261 \\
$D I P I$ & $-5.1611^{* * *}$ & $-109.2813^{* * * *}$ & 0.0764 \\
$D C P I$ & $-5.1379^{* * *}$ & $-6.5952^{* * *}$ & $0.3938^{*}$ \\
$D R S V I$ & $-7.1822^{* * *}$ & $-17.2447^{* * *}$ & 0.1551 \\
$D E N E R$ & $-12.3485^{* * *}$ & $-12.3859^{* * *}$ & 0.1030 \\
$D N O N E$ & $-10.3621^{* * *}$ & $-10.5900^{* * *}$ & 0.1363 \\
$D P M E T$ & $-14.4650^{* * *}$ & $-14.4561^{* * *}$ & 0.2476 \\
\hline$U_{-} D P R O D$ & $-17.7885^{* * *}$ & $-17.7871^{* * *}$ & $0.3737^{*}$ \\
$U_{-} R E A L$ & $-16.6241^{* * *}$ & $-16.6241^{* * *}$ & 0.0949 \\
$U_{-} D R P O$ & $-16.4409^{* * *}$ & $-16.4409^{* * *}$ & 0.0296 \\
$U_{-} D R E E R$ & $-15.8332^{* * *}$ & $-15.8614^{* * *}$ & 0.1461 \\
$U_{-} D I P I$ & $-4.8440^{* * *}$ & $-16.5912^{* * *}$ & 0.1113 \\
$U_{-} D C P I$ & $-17.0022^{* * *}$ & $-17.0016^{* * *}$ & 0.2734 \\
\hline
\end{tabular}

Note: $*, * *$ and $* * *$ indicate the significance levels at $10 \%, 5 \%$ and $1 \%$ respectively.

in the matrix which are DPROD, REAL, DRPO,DREER, DIPI and DCPI, and they are arranged in a sequence. $D P R O D$ is interpreted as an oil supply shock, while $R E A L$ and $D R P O$ are interpreted as oil aggregate demand shock and oil specific-demand shock respectively. The identified accumulated long-run impact matrix is a in lower triangular Cholesky decomposition. The first variable, which is DPROD has an influential effect on all variables below it, which are REAL, DRPO, DREER, DIPI and DCPI, but it is only affected by its own shock and is not affected by them. The second variable, $R E A L$, can affect all variables below it, which are DRPO, DREER, DIPI and DCPI, but it cannot give impact to the variable above it that is DPROD; however, $R E A L$ will receive effect from DPROD and its own shock but not from others. This rule of interpretation of the matrix is applied to all succeeding variables. The long-run impact matrix is identified to have a lower diagonal form while the contemporaneous matrix is unrestricted.

The result of the long-run impact matrix shows that the last variable which is CPI inflation is mainly affected by its own shock and exchange rate changes while the second last variable output growth is determined by its own shock, exchange rate changes and oil specific-demand shock. The oil supply shock and oil aggregate demand shock have no significant effect on both domestic variables in both the short run and long run. However, the oil aggregate demand shock has an inverse impact on the real effective exchange rate and the exchange rate changes is also influenced by its own shock. In addition, all variables are dominated by their own shocks in the long run. On the other hand, the estimated contemporaneous impact matrix shows that the oil aggregate demand receives large and significant influences from DREER shock, IPI 
inflation shock, CPI inflation shock and its own shock in the short run, while the short-run impact among each shock and variables for others are relatively small.

Overall, it is observed that oil supply shock does not lead to any significant effect on the global economic variables in both short-run and long-run periods. Oil demand and oil specificdemand shocks impose some effects on the global economic indicators in both short-run and long-run periods. However, the CPI inflation is not affected by any oil source shock in the long-run.

\subsubsection{Threshold Estimation}

All variables are tested for the presence of threshold effects prior to the threshold regression. If the null hypothesis of no threshold effect is rejected at $1 \%$ or $5 \%$ significance levels, then the threshold regression model is performed. The global economic indicators of consumer price inflation, industrial production price inflation and commodity price inflation (energy, nonenergy and precious metals sectors) are treated as the dependent variable while all shocks entered as explanatory variables. All variables (including the shock series) are tested as threshold variables.

Table 3 summarizes the results of the threshold effect test, i.e. the LM F-statistics with the significance levels. The threshold values are detected in majority cases as the threshold test shows high likelihood or high possibility on the existence of threshold values in these cases. The F-stat on the joint test on the null hypothesis is rejected, indicating the presence of threshold relationship. The dependent variables DENER and DIPI have detected two threshold variables while DNONE, DCPI and DPMET are determined by four threshold variables.

Table 4 summarises the linear regression using ordinary least squares (OLS) estimation. Comparing the results of linear versus nonlinear/ threshold regression, we observe that OLS is less accurate compared to threshold regression. For instance, the industrial production price inflation $(D I P I)$ shows different responses to different shocks as triggered by DCPI and DRSVI (threshold variables), see Table 5. When DCPI and DRSVI are treated as the threshold variables, an increase in industrial production shock causes higher industrial production price inflation in both regimes. This result is consistent with that reported in OLS, i.e.DIPI shock as the only significant factor. However, the impact of CPI shock in regime 1 under DCPI is a threshold is not detected in OLS.

Moving to DENER (Table 5), we observe from OLS estimation that the significant explanatory variables are $U_{-} D R P O$ (leading to higher DENER) and $U_{-} D R E E R$ (leading to lower DENER). The threshold regression shows that $U_{-} D R P O$ leads to higher DENER in both regimes when DNONE and $U_{-} D R P O$ are threshold variables. However, other significant impacts are also observed from $U_{-} R E A L$ and $U_{-} D R E E R$ (regime 1) and $U_{-} D C P I$ (regime 2) triggered by DRPO as the threshold variable. These effects fail to be detected under OLS estimation.

We compare the results of linear regression with that of threshold regression in Tables 5 and 6. From the threshold estimation, it can be seen that the non-energy sector is explained well by DPROD (oil supply) shock and DRPO (oil specific-demand) shock under certain threshold variables, while the energy sector is determined by DRPO (oil specific-demand) shock. Hence, oil source and sectoral of production matter in determining the oil effect. Although SVAR estimation shows that oil supply shock has no significant effect on the macro variables while 
Table 3: Threshold Test of All Variables for the Five Dependent Variables

\begin{tabular}{|c|c|c|c|c|c|}
\hline Threshold variable & $D E N E R$ & $D N O N E$ & DPMET & $D I P I$ & $D C P I$ \\
\hline DREER & 16.0415 & $16.2224^{*}$ & $18.4098^{* *}$ & 13.9593 & $18.4867^{* *}$ \\
\hline$D I P I$ & 10.7989 & 9.5448 & 13.8174 & - & $24.0793^{* * *}$ \\
\hline$D C P I$ & 14.8391 & 11.5864 & $17.0798^{*}$ & $34.2840^{* * *}$ & - \\
\hline$D R S V I$ & 11.1677 & $19.4661^{* *}$ & 16.6685 & $25.9379^{* * *}$ & 13.4888 \\
\hline DENER & - & $22.1068^{* * *}$ & 15.2232 & 13.1507 & 14.772 \\
\hline$D N O N E$ & $29.6063^{* * *}$ & - & $32.1344^{* * *}$ & 13.0082 & 10.6021 \\
\hline$D P M E T$ & 12.1315 & $26.5653^{* * *}$ & - & 12.3173 & 9.8951 \\
\hline$U_{-} D P R O D$ & 12.605 & 13.3824 & $17.3371^{*}$ & 11.296 & 12.9026 \\
\hline$U \_R E A L$ & 15.5547 & 9.4026 & 14.1698 & 12.345 & $19.0931^{* *}$ \\
\hline$U_{-} D R P O$ & $18.7130^{* *}$ & $18.0229 * *$ & 9.4454 & 11.4272 & 11.8223 \\
\hline$U_{-} D R E E R$ & 14.8149 & 12.6977 & $18.9429^{* *}$ & $18.2953^{*}$ & 13.389 \\
\hline U_DIPI & 10.5253 & 9.846 & $19.0248^{* *}$ & 14.2943 & $18.1237^{* *}$ \\
\hline$U_{-} D C P I$ & 9.6879 & 14.8896 & 9.4317 & $16.8378^{*}$ & 15.9538 \\
\hline \multirow{4}{*}{$\begin{array}{c}\text { Threshold } \\
\text { variable } \\
\text { selected }\end{array}$} & $D N O N E$ & $D R S V I$ & $D R E E R$ & $D C P I$ & $D I P I$ \\
\hline & $U_{-} D R P O$ & $D P M E T$ & DNONE & $D R S V I$ & $U_{-} R E A L$ \\
\hline & & $U_{-} D R P O$ & $U_{-} D R E E R$ & & $D R E E R$ \\
\hline & & DENER & $U_{-} D I P I$ & & $U_{-} D I P I$ \\
\hline
\end{tabular}

Note: Values reported are LM F-test statistics; $*$, ** and $* * *$ indicate the significance levels at $10 \%, 5 \%$ and $1 \%$ respectively.

Table 4: The Linear Regression - OLS Estimation

\begin{tabular}{cccccc}
\hline Variable & $\boldsymbol{D I P I}$ & $\boldsymbol{D C P I}$ & $\boldsymbol{D E N E R}$ & $\boldsymbol{D N O N E}$ & $\boldsymbol{D P M E T}$ \\
\hline Intercept & 0.0009 & $0.0032^{* * *}$ & 0.0012 & 0.0011 & $0.0042^{*}$ \\
$U_{-} D P R O D$ & -0.0151 & -0.001 & -0.0735 & -0.0059 & 0.0345 \\
$U_{-} R E A L$ & 0.0002 & 0 & 0.0002 & $0.0005^{* *}$ & 0.0003 \\
$U_{-} D R P O$ & 0.0196 & -0.0002 & $0.7956^{* * *}$ & $0.0785^{* * *}$ & 0.0333 \\
$U_{-} D R E E R$ & 0.324 & -0.0004 & $-1.5751^{* *}$ & $-1.9438^{* * *}$ & $-3.3626^{* * *}$ \\
$U_{-} D I P I$ & $1.0062^{* * *}$ & -0.008 & -0.0203 & -0.0121 & -0.0049 \\
$U_{-} D C P I$ & -1.0499 & $1.0003^{* * *}$ & $3.0118^{*}$ & $2.8406^{* * *}$ & $2.3665^{*}$ \\
\hline
\end{tabular}

Note: ${ }^{*}, * *$ and ${ }^{* * *}$ indicate the significance levels at $10 \%, 5 \%$ and $1 \%$ respectively. 
Table 5: Threshold Regression Models (Dependent: DIPI and DENER)

\begin{tabular}{|c|c|c|c|c|}
\hline \multirow{2}{*}{ Variable } & \multicolumn{2}{|c|}{ Dependent: $D I P I$} & \multicolumn{2}{|c|}{ Dependent: $D E N E R$} \\
\hline & Regime 1 & Regime 2 & Regime 1 & Regime 2 \\
\hline & $D C P I \leqslant 0.0028$ & $D C P I>0.0028$ & $D N O N E \leqslant-0.0213$ & DNONE >-0.0213 \\
\hline Intercept & $-0.0135^{* * *}$ & $0.0096^{* *}$ & $-0.0256^{* * *}$ & $0.0072^{* * *}$ \\
\hline$U_{-} D P R O D$ & -0.0407 & -0.1359 & 0.029 & $-0.1020^{*}$ \\
\hline$U_{-} R E A L$ & -0.0003 & $0.0007^{*}$ & 0.001 & -0.0001 \\
\hline$U_{-} D R P O$ & $0.0767 * *$ & -0.0322 & $0.9852^{* * *}$ & $0.7133^{* * *}$ \\
\hline$U_{-} D R E E R$ & $1.1808^{*}$ & -0.2579 & -0.8361 & -0.4914 \\
\hline$U_{-} D I P I$ & $0.8849^{* * *}$ & $1.1184^{* * *}$ & 0.1543 & 0.0128 \\
\hline$U_{-} D C P I$ & $-9.7331^{* * *}$ & -0.2441 & 1.456 & 2.5623 \\
\hline & $D R S V I \leqslant 0.0153$ & $D R S V I>0.0153$ & $U_{-} D R P O \leqslant-0.0408$ & $U_{-} D R P O>-0.0408$ \\
\hline Intercept & $0.0046^{* *}$ & $-0.0327 * * *$ & 0.0099 & $0.0077^{* * *}$ \\
\hline$U_{-} D P R O D$ & -0.0038 & -0.0047 & 0.0023 & $-0.0943^{*}$ \\
\hline$U_{-} R E A L$ & 0.0002 & 0.0008 & $0.0016^{* * *}$ & -0.0003 \\
\hline$U_{-} D R P O$ & 0.0173 & $0.1797^{*}$ & $0.9860 * * *$ & $0.6644^{* * *}$ \\
\hline$U_{-} D R E E R$ & -0.075 & -0.6472 & $-3.5706 * *$ & -0.0085 \\
\hline$U_{-} D I P I$ & $1.0422^{* * *}$ & $0.9367 * * *$ & -0.0015 & 0.0177 \\
\hline$U_{-} D C P I$ & -0.4715 & -5.4717 & -2.2625 & $5.2138^{* * *}$ \\
\hline
\end{tabular}

oil aggregate demand and oil specific-demand shocks have small effects on macro variables, threshold regression reveals deeper information when asymmetric/ threshold effect exists that leads to quite different results. The one consistent result found in both SVAR and threshold regression estimations is each macro variable is dominated by its own shock.

To conclude, among the shock effects of three oil sources, the oil specific-demand shock is more influential. The oil specific-demand shock has highly significant impacts on the energy and non-energy sectors while the oil aggregate demand shock does not have a large impact on any of the economic indicators. However, the oil supply shock shows a rather large and significant effect on the non-energy sector only. Hence, the global economy is oil demand-driven. This result is consistent with Kilian (2009) who claimed that the oil demand origin shocks are more determined. Besides that, the impact of oil is relatively large in the energy sector when compared to the non-energy sector and precious metals industry. One of the possible reasons is that crude oil is a source of energy which is widely used in the energy industry besides natural gas. Table 7 summarises the main determinants for each dependent variable.

\section{Conclusion}

This study seeks to fill the limitations of traditional studies The two main limitations are the data construction and the regression approach. Traditional studies used oil prices (supplydriven) to proxy for oil shock, and the demand sources of oil shock were neglected. Also, most studies only applied linear regression while the theoretical model has recognised the asymmetric 
Table 6: Threshold Regression Models (Dependent: DCPI, DNONE, DPMET)

\begin{tabular}{|c|c|c|c|c|c|c|}
\hline \multirow{2}{*}{ Variable } & \multicolumn{2}{|c|}{ Dependent: $D C P I$} & \multicolumn{2}{|c|}{ Dependent: $D N O N E$} & \multicolumn{2}{|c|}{ Dependent: $D P M E T$} \\
\hline & Regime 1 & Regime 2 & Regime 1 & Regime 2 & Regime 1 & Regime 2 \\
\hline & $D R E E R \leqslant$ & DREER > & $D R S V I \leqslant$ & $D R S V I>$ & $D R E E R \leqslant$ & DREER > \\
\hline & 0.0045 & 0.0045 & -0.0076 & -0.0076 & 0.0007 & 0.0007 \\
\hline Intercept & $0.0029^{* * *}$ & $0.0042^{* * *}$ & -0.0026 & 0.0022 & $0.0124^{* * *}$ & -0.0051 \\
\hline$U_{-} D P R O D$ & -0.0028 & $-0.0183^{*}$ & $-0.7059^{* * *}$ & 0.0643 & 0.1347 & -0.0477 \\
\hline$U_{-} R E A L$ & 0 & $-0.0001^{* * *}$ & $0.0022^{* * *}$ & 0.0002 & -0.0002 & 0.0007 \\
\hline$U_{-} D R P O$ & 0.0041 & -0.0082 & 0.0592 & $0.0572^{* * *}$ & 0.0331 & 0.006 \\
\hline$U_{-} D R E E R$ & -0.023 & -0.2588 & $-3.0476^{* * *}$ & $-1.5362^{* * *}$ & -1.727 & -1.7523 \\
\hline$U_{-} D I P I$ & -0.0053 & -0.0319 & $-0.3593^{* * *}$ & 0.0348 & -0.0332 & 0.0604 \\
\hline \multirow[t]{3}{*}{$U_{-} D C P I$} & $0.4945^{* * *}$ & $2.3281^{* * *}$ & 1.7704 & $2.6379^{* *}$ & $6.9309^{* * *}$ & 0.5017 \\
\hline & $D I P I \leqslant$ & $D I P I>$ & $D E N E R \leqslant$ & DENER > & $D N O N E \leqslant$ & $\overline{D N O N E}>$ \\
\hline & 0.0032 & 0.0032 & -0.12 & -0.12 & -0.0447 & -0.0447 \\
\hline Intercept & $0.0025^{* * *}$ & $0.0037^{* * *}$ & 0.0247 & $0.0034^{* * *}$ & $-0.1296^{* * *}$ & $0.0055^{* *}$ \\
\hline$U_{-} D P R O D$ & -0.0109 & 0.0017 & $0.3505^{* * *}$ & -0.0185 & -0.0925 & 0.0429 \\
\hline$U_{-} R E A L$ & 0 & 0.0001 & $0.0014^{*}$ & 0.0002 & $0.0030^{* * *}$ & 0.0002 \\
\hline$U_{-} D R P O$ & 0.0002 & -0.0037 & 0.288 & $0.0327^{*}$ & $-1.0770^{* * *}$ & 0.0372 \\
\hline U_DREER & 0.0275 & -0.0572 & -2.6692 & $-1.6989 * * *$ & $-12.6763^{* * *}$ & $-2.9142^{* * *}$ \\
\hline$U_{-} D I P I$ & $-0.0328 * *$ & -0.0109 & 0.3738 & -0.017 & $1.4978^{* * *}$ & -0.0135 \\
\hline \multirow[t]{2}{*}{$U_{-} D C P I$} & $1.3471^{* * *}$ & $0.7995^{* *}$ & $17.1503^{* *}$ & $2.5072^{* * *}$ & -13.8994 & 1.8434 \\
\hline & $\begin{array}{c}U_{-} R E A L \leqslant \\
7.0549\end{array}$ & $\begin{array}{c}U_{-} R E A L> \\
-7.0549\end{array}$ & $\begin{array}{c}D P M E T \leqslant \\
-0.0588\end{array}$ & $\begin{array}{c}D P M E T> \\
-0.0588\end{array}$ & $\begin{array}{c}U_{-} D R E E R \leqslant \\
-0.0004\end{array}$ & $\begin{array}{c}U_{-} D R E E R> \\
-0.0004\end{array}$ \\
\hline Intercept & $0.0036^{* * *}$ & $0.0029^{* * *}$ & 0.0109 & $0.0030^{* *}$ & $0.0145^{* * *}$ & -0.0026 \\
\hline$U_{-} D P R O D$ & $0.0160^{*}$ & -0.0039 & $-1.7849^{* * *}$ & 0.0576 & 0.0656 & 0.0453 \\
\hline$U_{-} R E A L$ & 0 & $0.0001^{*}$ & 0.0009 & 0.0002 & -0.0005 & $0.0008^{*}$ \\
\hline$U_{-} D R P O$ & 0.007 & -0.001 & $-0.5467 * * *$ & $0.0631^{* * *}$ & 0.0152 & 0.019 \\
\hline U_DREER & 0.1751 & -0.0406 & $-9.4290 * * *$ & $-1.4418^{* * *}$ & -1.5391 & -1.6453 \\
\hline$U_{-} D I P I$ & -0.0276 & -0.0066 & $1.1484^{* * *}$ & -0.017 & -0.1143 & 0.1021 \\
\hline \multirow[t]{2}{*}{$U_{-} D C P I$} & $1.9058^{* * *}$ & $0.7058^{* *}$ & $10.4673^{* * *}$ & $2.6343^{* * *}$ & $8.1867^{* * *}$ & 0.3145 \\
\hline & $\begin{array}{c}U_{-} D I P I \leqslant \\
0.0156\end{array}$ & $\begin{array}{c}U_{-} D I P I> \\
0.0156\end{array}$ & $\begin{array}{c}U_{-} D R P O \\
-0.1512\end{array}$ & $\begin{array}{c}U_{-} D R P O> \\
-0.1512\end{array}$ & $\begin{array}{c}U_{-} D I P I \leqslant \\
-0.0331\end{array}$ & $\begin{array}{c}U_{-} D I P I> \\
-0.0331\end{array}$ \\
\hline Intercept & $0.0031^{* * *}$ & $0.0021^{* * *}$ & $-0.2393^{* *}$ & 0.0019 & 0.0537 & 0.0026 \\
\hline$U_{-} D P R O D$ & -0.0073 & 0.0036 & $-0.3215^{* *}$ & 0.0276 & $1.0680^{* *}$ & -0.0004 \\
\hline$U_{-} R E A L$ & 0 & 0 & $0.0046 * * *$ & $0.0004^{*}$ & $0.0049^{* * *}$ & -0.0001 \\
\hline$U_{-} D R P O$ & -0.0035 & 0.0066 & $-1.3929 * * *$ & $0.0557^{* * *}$ & $0.2168^{* *}$ & 0.0447 \\
\hline$U_{-} D R E E R$ & 0.03 & -0.0753 & $-11.8529 * * *$ & $-1.7181^{* * *}$ & $-5.1375^{* *}$ & $-3.3447 * * *$ \\
\hline$U_{-} D I P I$ & -0.0155 & 0.0183 & $2.9168^{* * *}$ & -0.018 & 1.1394 & 0.1034 \\
\hline$U_{-} D C P I$ & $1.4300^{* * *}$ & 0.2174 & $-12.6180^{*}$ & $2.8037^{* * *}$ & -3.0821 & 1.9424 \\
\hline
\end{tabular}

Note: ${ }^{*},{ }^{* *}$ and ${ }^{* * *}$ indicate the significance levels at $10 \%, 5 \%$ and $1 \%$ respectively. 
Table 7: A Summary of the Threshold Results

\begin{tabular}{cc}
\hline $\boldsymbol{Y}$ & Main Explanatory Factor (Sign Effect) \\
\hline$D I P I$ & $U_{-} D I P I(+), U_{-} D C P I(-)$ \\
$D C P I$ & $U_{-} D C P I(+)$ \\
$D E N E R$ & $U_{-} D R P O(+), U_{-} D R E E R(-), U_{-} D C P I(+)$ \\
$D N O N E$ & $U_{-} D P R O D(+/-), U_{-} D R P O(+/-), U_{-} D R E E R(-), U_{-} D C P I(+)$ \\
$D P M E T$ & $U_{-} D R E E R(-), U_{-} D C P I(+)$ \\
\hline
\end{tabular}

effect of an oil shock. Based on these issues, this study applied the data decomposition of Kilian [4] to distinguish oil shocks into demand versus supply origins. We also applied the nonlinear/ threshold regression of Hansen [5] to capture the asymmetric effect of oil shock on the global economic indicators, i.e., CPI inflation, IPI inflation and commodity price inflation (energy, non-energy and precious metals sectors). Our results reveal the varying effects of oil shocks triggered by threshold variables across two regimes. Threshold regression provides more informative and accurate estimates compared to OLS estimates.

The oil specific-demand shock has a greater impact on the global economy than the oil supply shock while the oil aggregate demand shock shows no significant impact. Despite that, the impact of oil shocks is small if compared to the non-oil shocks such as exchange rate changes and CPI inflation shock. Consequently, non-oil shocks are the main determinants of the global economic fluctuation. In order to reduce the negative effects from the exchange rate changes and CPI inflation shock, the monetary policy has to be set to maintain price stability especially for the necessary goods such as food, utilities, communications, housing, transportation, medicine, education and services. The policymakers can also reduce interest rates or give subsidies to those goods.

\section{Acknowledgments}

This project is part of the research funded by Bridging Grant, Universiti Sains Malaysia (304.PMATHS.6316359).

\section{References}

[1] Yusgiantoro, P. Petroleum will still be the major energy resource in the 21st century. 2004. Retrieved $28^{\text {th }}$ February 2019, from https://www.opec.org/opec_web/en/902.htm

[2] Ritchie, H. and Roser, M. Fossil fuels. 2019. Retrieved $7^{\text {th }}$ March 2019,from https://ourworldindata.org/fossil-fuels

[3] Lioudis, N. K. The relationship between oil prices and inflation. 2018. Retrieved $1^{\text {st }}$ March 2019, from https://www.investopedia.com/ask/answers/06/oilpricesinflation.asp

[4] Kilian, L. Not all oil price shocks are alike: Disentangling demand and supply shocks in the crude oil market. American Economic Review. 2009. 99(3): 1053-1069.

[5] Hansen, B. E. Sample splitting and threshold estimation. Econometrica. 2000. 68(3): 575603. 
[6] Kilian, L. Oil price shocks: Causes and consequences. Annual Review of Resource Economics. 2014. 6(1): 133-154.

[7] Tang, W., Wu, L. and Zhang, Z. X. Oil price shocks and their short- and long-term effects on the Chinese economy. 2009. MPRA Paper No. 14703, available athttp://mpra.ub.unimuenchen.de/14703/

[8] Maina, G. P. Transmission Channels of Crude Oil Price Shocks on Kenya's Economy. Master's Thesis. Kenyatta University. 2015.

[9] LeBlanc, M. and Chinn, M. D. Do high oil prices presage inflation? The evidence from g-5 countries. 2004. SCCIE Working Paper No. 04-4, available at http:// repositories.cdlib.org/sccie/04-04

[10] L'oeillet, G. and Licheron, J. Oil prices and inflation in the euro area: A nonlinear and unstable relationship. In 5èmes doctoriales MACROFI 2008, May 22-23. Aix-en-Provence, France. 2008. 1-23.

[11] Baumeister, C., Peersman, G. and Robays, I. V. The economic consequences of oil shocks: Differences across countries and time. In Fry, R., Jones, C. and Kent, C.(Eds.).Inflation in an Era of Relative Price Shocks. Sydney: Reserve Bank of Australia. 2010. 91-137.

[12] Peersman, G. and Robays, I. V. Cross-country differences in the effects of oil shocks. Energy Economics. 2012. 34(5): 1532-1547.

[13] Jiménez-Rodríguez, R. and Sánchez, M. Oil price shocks and real GDP growth: Empirical evidence for some OECD countries. Applied Economics. 2005. 37(2): 201-228.

[14] Filis, G. and Chatziantoniou, I. Financial and monetary policy responses to oil price shocks: Evidence from oil-importing and oil-exporting countries. Review of Quantitative Finance and Accounting. 2014. 42(4): 709-729.

[15] Mensi, W. Global financial crisis and co-movements between oil prices and sector stock markets in Saudi Arabia: A VaR based wavelet. Borsa Istanbul Review Volume. 2019. 19(1): $24-38$.

[16] Arouri, M. E. H. and Nguyen, D. K. Oil prices, stock markets and portfolio investment: Evidence from sector analysis in Europe over the last decade. Energy Policy. 2010. 38(8): 4528-4539.

[17] Hooker, M. A. Are oil shocks inflationary? Asymmetric and nonlinear specifications versus changes in regime. Journal of Money, Credit and Banking. 2002. 34(2): 540-561.

[18] Herrera, A. M. and Pesavento, E. Oil price shocks, systematic monetary policy, and the "great Moderation". Macroeconomic Dynamics. 2009. 13(1): 107-137.

[19] Al-hajj, E., Al-Mulali, U. and Solarin, S. A. Oil price shocks and stock returns nexus for Malaysia: Fresh evidence from nonlinear ARDL test. Energy Reports. 2018. 4: 624-637.

[20] Bastianin, A., Conti, F. and Manera, M.The impacts of oil price shocks on stock market volatility: Evidence from the G7 countries. Energy Policy. 2016. 98: 160-169.

[21] Castillo, P., Montoro, C. and Tuesta, V. Inflation, oil price volatility and monetary policy. 2010. RePEcWorking Papers2010-002, available at https://ideas.repec.org/p/rbp/wpaper/2010-002.html 
[22] Trang, N. T. N., Tho, T. N. and Hong, D. T. T. The impact of oil price on the growth, inflation, unemployment and budget deficit of Vietnam. International Journal of Energy Economics and Policy. 2017. 7(3): 42-49.

[23] Jiranyakul, K. Oil price shocks and domestic inflation in Thailand. 2018. MPRA Paper No. 87699, available at https://mpra.ub.uni-muenchen.de/87699/

[24] Olomola, P. A. and Adejumo, A. V. Oil price shock and macroeconomic activities in Nigeria. International Research Journal of Finance and Economics. 2006. 3: 1-8.

[25] Trehan, B. Oil price shocks and inflation. FRBSF Economic Letter. 2005. 28: 1-3.

[26] Al-mulali, U. and Sab, C. N. C. The impact of oil shocks on Qatar's GDP. 2010. MPRA Paper No. 27822, available at http://mpra.ub.uni-muenchen.de/27822/

[27] Gbatu, A. P., Wang, Z., Wesseh, P. K. and Tutdel, I. Y. R. The impacts of oil price shocks on small oil-importing economies: Time series evidence for Liberia. Energy. 2017. 139: 975-990.

[28] Zhang, C. and Chen, X. The impact of global oil price shocks on China's bulk commodity markets and fundamental industries. Energy Policy. 2014. 66: 32-41.

[29] Melichar, M. and Atems, B. Global crude oil market shocks and global commodity prices. OPEC Energy Review. 2019. 43(1): 92-105.

[30] Fowowe, B. Do oil prices drive agricultural commodity prices? Evidence from South Africa. Energy. 2016. 104: 149-157.

[31] Sek, S. K. Unveiling the factors of oil versus non-oil sources in affecting the global commodity prices: A combination of threshold and asymmetric modelling approach. Energy. 2019. 176: 272-280.

[32] Ibrahim, M. H. Oil and food prices in Malaysia: A nonlinear ARDL analysis. Agricultural and Food Economics. 2015. 3(2): 1-14.

[33] Sotoudeh, M. A. and Worthington, A. C. Nonlinear effects of oil prices on consumer prices: A comparative study of net oil consuming and producing countries. Review of Economic Analysis. 2017. 9: 57-79.

[34] Oyelami, L. O. Effects of oil price movement on Nigerian macroeconomic variables: evidence from linear near and nonlinear ARDL modelling. Iranian Economic Review. 2018. 22(4): 908-933.

[35] Güntner, J. H. F. and Linsbauer, K. The effects of oil supply and demand shocks on U.S. consumer sentiment.2016. Working Paper No. 1614, available at http://hdl.handle.net/10419/162457

[36] Kilian, L.Lutz Kilian's website. Retrieved $16^{\text {th }}$ January 2019, from http://wwwpersonal.umich.edu/ lkilian/

[37] Global Economic Monitor. 2010. Retrieved $16^{\text {th }}$ January 2019, from https:// datacatalog.worldbank. org/dataset/global-economic-monitor

[38] Commodity Markets. 2019. Retrieved 16 ${ }^{\text {th }}$ January 2019, from http:// www.worldbank.org/en/research/commodity-markets

[39] Blanchard, O. J. and Quah, D. The dynamic effects of aggregate demand and supply disturbances. The American Economic Review. 1989. 79(4): 655-673. 
[40] Kilian, L. and Park, C. The impact of oil price shocks on the U.S. stock market. International Economic Review. 2009. 50(4): 1267-1287.

[41] Lütkepohl, H. Impulse Response Function. InDurlauf, S. N. and Blume, L. E. (Eds.). The New Palgrave Dictionary of Economics. London: Palgrave Macmillan. 2008. 2872-2875.

[42] Akaike, H. A new look at the statistical model identification. IEEE Transactions on Automatic Control. 1974. 19(6): 716-723. 